Article

\title{
Resolving the Acid Site Distribution in Zn-Exchanged ZSM-5 with Stimulated Raman Scattering Microscopy
}

\author{
Guillaume Fleury (10) and Maarten B. J. Roeffaers *(1) \\ Centre for Membrane Separations, Adsorption, Catalysis and Spectroscopy for Sustainable Solutions (cMACS), \\ Department of Microbial and Molecular Systems, KULeuven, Celestijnenlaan 200F, 3001 Leuven, Belgium; \\ guillaume.fleury@kuleuven.be \\ * Correspondence: maarten.roeffaers@kuleuven.be; Tel.: +32-16327449
}

Received: 27 October 2020; Accepted: 13 November 2020; Published: 16 November 2020

\begin{abstract}
Zeolites are widely used acid catalysts in research and in industrial processes. The catalytic performance of these materials is affected by the nature and concentration of Brønsted and Lewis acid sites. The balance between these types of active sites-and thus the activity and selectivity of the zeolite - can be altered by the introduction of metal species, e.g., by ion exchange. Although the acidic properties of zeolites are routinely characterized by bulk-scale techniques, this ensemble-averaged approach neglects the local variations in the material. Insights into the distribution of active sites at the single-particle level are thus critical to better understand the impact of post-synthetic modifications on the zeolite acidity. In this contribution, we spatially resolve Brønsted and Lewis acid sites in protonated and Zn-exchanged ZSM-5 crystals. To this end, the vibrational modes of pyridine chemisorbed on active sites are mapped with stimulated Raman scattering (SRS) microscopy. The SRS images reveal sharp inter- and intra-particle heterogeneities in the distribution of Lewis acid sites introduced upon ion exchange, ascribed to local variations in the $\mathrm{Al}$ content. Besides assessing the impact of Zn exchange on the active site distribution in ZSM- 5 crystals, this approach enables uniquely to map the distribution of Lewis acid sites in catalysts at the single-particle level.
\end{abstract}

Keywords: zeolites; ion exchange; Lewis acid sites; Raman spectroscopy; microscopy

\section{Introduction}

The petrochemical industry relies on heterogeneous catalysts to optimize the conversion and selectivity of chemical processes [1]. The nature, concentration, and distribution of active sites are critical parameters to rationalize the catalytic activity of solid acid catalysts. The active sites of these materials consist of Brønsted and Lewis acid sites, i.e., proton donors and electron acceptors. Besides Brønsted acid sites, acidic heterogeneous catalysts also heavily rely on Lewis acidity [2-4].

In zeolites, Brønsted acidity originates from charge-balancing protons, whereas extra-framework Al-species and framework Al defects give rise to Lewis acid sites. The Lewis acidity of zeolites can be enhanced by introducing extra-framework cationic species such as transition metal complexes [5]. These modifications enable fine-tuning of the acidic properties of zeolites and thus of their catalytic performance. Among these modified zeolites, Zn-substituted ZSM-5 has attracted significant interest in the field of catalysis over the years, as the strong Lewis acidity arising from $\mathrm{Zn}$ species greatly enhances the selectivity for aromatic products in the conversion of light alkanes to hydrocarbons [6-11].

The additional species introduced in catalytic materials through post-synthetic modifications can display heterogeneities in their local properties (e.g., geometry, electronic state) [12]. The state of these species and their local environment can be accurately probed with spectroscopic tools such as solid-state nuclear magnetic resonance (SS-NMR), electron paramagnetic resonance (EPR) and X-ray absorption spectroscopy [13-15]. For instance, extended X-ray absorption fine structure (EXAFS) 
enables distinguishing $\mathrm{Zn}$ species incorporated in ZSM-5 as isolated $\mathrm{Zn}^{2+}$ and $\mathrm{ZnO}$ clusters [11,16]. In addition to EXAFS, Biscardi et al. also used temperature-programmed reduction to distinguish these two Zn species and gain insights into the structure of isolated $\mathrm{Zn}^{2+}$ in ZSM-5 [11].

Besides heterogeneities in their local environment, the additional metal species can also be non-uniformly introduced in individual catalyst particles, irrespective of the size of the catalyst and the method used [17]. Spatially resolved characterization tools are thus required to probe the distribution of these species. Therefore, recent decades have seen a significant endeavor to develop microscopy methodologies to resolve the spatial heterogeneities of these materials at the single-particle level [18-21]. For instance, the characterization of metal-impregnated $\mathrm{Al}_{2} \mathrm{O}_{3}$ pellets with 2D MRI imaging and tomographic energy-dispersive diffraction imaging revealed egg-shell and egg-yolk patterns for the distribution of metal species $[17,22]$. Furthermore, optical microscopic characterization of Ag-loaded $\mathrm{SiO}_{2}$ granules revealed sharp interparticle variations in the silver content [23,24]. Besides large catalyst bodies, inhomogeneities have also been observed in sub-micrometer zeolite materials. The phosphatation of ZSM- 5 was investigated at the single-particle level with scanning transmission X-ray microscopy, demonstrating the inhomogeneous distribution of phosphorus moieties in the intergrown zeolite clusters [25]. Likewise, significant differences in the nanoparticle content of a Pt/zeolite Y catalyst were observed with electron tomography, with an average Pt loading of the crystals ranging from $0.2 \mathrm{wt}$. \% to $7.1 \mathrm{wt}$. \% [26]. On the other hand, elemental mapping of Zn-loaded ZSM- 5 and silicalite- 1 with energy dispersive $X$-ray spectroscopy (EDX) revealed a fairly homogeneous distribution of the metal species in zeolite particles [27].

Nevertheless, no studies investigated the impact of the post-synthetic modifications on the actual spatial distribution of Lewis acid sites at the single-particle level so far. Indeed, microscopic investigations of the active site distribution in catalyst particles have been mainly focused on Brønsted acidity $[17,18]$. This gap in imaging studies dedicated to the Lewis acidity is due to the lack of methodologies able to resolve the location of these active sites selectively. Fluorescence microscopy allows resolving the active site distribution in catalyst particles using the oligomerization of fluorogenic probes such as furfuryl alcohol and styrene derivates [28-30]. However, these reactions occur mainly on Brønsted acid sites, or simultaneously on Brønsted and Lewis acid sites [31]. Alternatively, the interactions of a probe molecule with both types of active sites can be distinguished using its vibrational modes [32]. Although this approach was used to map the active sites in zeolite crystals with infrared imaging and stimulated Raman scattering (SRS) microscopy, the reported images are exclusively focused on Brønsted acidity [33,34].

In this work, the acidic properties of zinc-exchanged ZSM-5 zeolites were investigated the single-particle level. More specifically, we map the distribution of Brønsted and Lewis acid sites in single ZSM-5 crystals at different exchange times with SRS microscopy, using pyridine as a probe molecule

\section{Results}

Three ZSM-5 samples were used in this study, starting from a commercial zeolite in the ammonium form $(\mathrm{Si} / \mathrm{Al}=20)$. The zeolite in its protonated form $(\mathrm{Zn} 000)$ was prepared by calcination of the parent sample. $\mathrm{Zn}$-containing zeolites were prepared by ion-exchanged of the parent sample with zinc nitrate for $30 \mathrm{~min}(\mathrm{Zn} 030)$ and $6 \mathrm{~h}$ (Zn600) and subsequent calcination. The exact $\mathrm{Zn}$ content of the three samples was determined by X-ray fluorescence (XRF) (Table 1). The texture of the materials was characterized by nitrogen physisorption (Figure S1). The surface area and the pore volume of the protonated and zinc-exchanged samples indicate that the incorporation of $\mathrm{Zn}$ does not significantly affect the porous properties of the zeolite (Table S1). Furthermore, all ZSM-5 zeolites exhibit the characteristic X-ray diffraction (XRD) pattern of the MFI framework (Figure S2a). The introduction of $\mathrm{Zn}$ species does not affect the framework structure as no significant loss in the intensity of the diffraction peaks is observed upon ion exchange. Furthermore, the characteristic reflections related to $\mathrm{ZnO}$ are not distinguishable in the XRD pattern of the exchanged materials, suggesting that the $\mathrm{Zn}$ species are highly dispersed (Figure S2b). The absence of $\mathrm{ZnO}$ clusters is also supported by the diffuse reflectance 
spectra of the exchanged zeolites as no new absorption band is observed in the 360-380 nm region (Figure S3). Therefore, zinc species in Zn030 and Zn600 are considered to be atomically dispersed inside the ZSM-5 framework as $\mathrm{Zn}^{2+}$ species at cation-exchange sites. This is in line with previous studies on the nature of $\mathrm{Zn}$ in ion-exchanged ZSM- 5 zeolites on which the preparation method was based $[9,11,35]$. However, the coordination of $\mathrm{Zn}$ species to framework oxygen in the vicinity of framework aluminum (denoted Zeo hereafter) is subject to debate. Indeed, Berndt et al. concluded that $\mathrm{Zn}^{2+}$ is incorporated in ZSM-5 as $\mathrm{Zeo}[\mathrm{Zn}(\mathrm{OH})]$, whereas Biscardi and coworkers observed $\mathrm{Zeo}_{2} \mathrm{Zn}$ species resulting from the coupling of $\mathrm{Zeo}[\mathrm{Zn}(\mathrm{OH})]$ with an acidic surface hydroxyl group nearby $[11,35]$.

Table 1. Zinc loading measured by XRF analysis and concentration of Brønsted and Lewis acid sites determined from Fourier-transformed infrared spectroscopy (FTIR) using pyridine as a probe molecule.

\begin{tabular}{cccc}
\hline & Zn Content (wt. \%) & $\begin{array}{c}\mathrm{C}_{\text {Bronsted }} \\
(\mu \mathrm{mol} / \mathrm{g})\end{array}$ & $\begin{array}{c}\mathrm{C}_{\text {Lewis }} \\
(\boldsymbol{\mu \mathrm { mol } / \mathrm { g } )}\end{array}$ \\
\hline Zn000 & 0 & 306 & 21 \\
\hline Zn030 & 1.04 & 209 & 165 \\
\hline Zn600 & 1.65 & 158 & 245 \\
\hline
\end{tabular}

The exchange of acid protons by $\mathrm{Zn}^{2+}$ species affects the nature and concentration of acid sites in zeolites. The impact of zinc exchange on the acidic properties of ZSM- 5 materials was investigated with Fourier transformed infrared (FTIR) spectroscopy by probing the in-plane $\mathrm{CH}$ and $\mathrm{NH}$ bending vibrational modes of chemisorbed pyridine. Figure 1a shows the FTIR spectra of pyridine chemisorbed in the protonated and Zn-exchanged ZSM-5 zeolites after evacuation at $150{ }^{\circ} \mathrm{C}$. The presence of Brønsted and Lewis acid sites is demonstrated by absorption bands at 1544 and $1454 \mathrm{~cm}^{-1}$, respectively [9]. The concentration of both types of acid sites was quantified using the area of the corresponding bands (Table 1). The concentration of Lewis acid sites increases with the $\mathrm{Zn}^{2+}$ ion exchange time, while the opposite trend is observed for Brønsted acid sites. Interestingly, the quantitative analysis of the FTIR spectra shows that the increase in Lewis acid sites exceeds the loss of Brønsted acid sites. Several authors have reported similar observations-especially for Zn incorporation in ZSM- 5 by ion exchange-although the origin of this phenomenon remains unclear so far [9,36-38] Pinialla-Herrero et al. suggested that $\mathrm{Zn}$ species interact with more than one pyridine molecule, leading to an apparent excess of Lewis acid sites [39]. In contrast, Valecillos et al. rationalized this uneven variation by the use of an inaccurate molar extinction coefficient for the new Lewis acid sites arising from the $\mathrm{Zn}^{2+}$ species [40]. In any case, it is clear from the FTIR data that new Lewis acid sites appear at the expense of Brønsted acid sites upon the exchange of protons by $\mathrm{Zn}$ species. However, these data do not provide information about the location of active sites in the zeolite crystals.
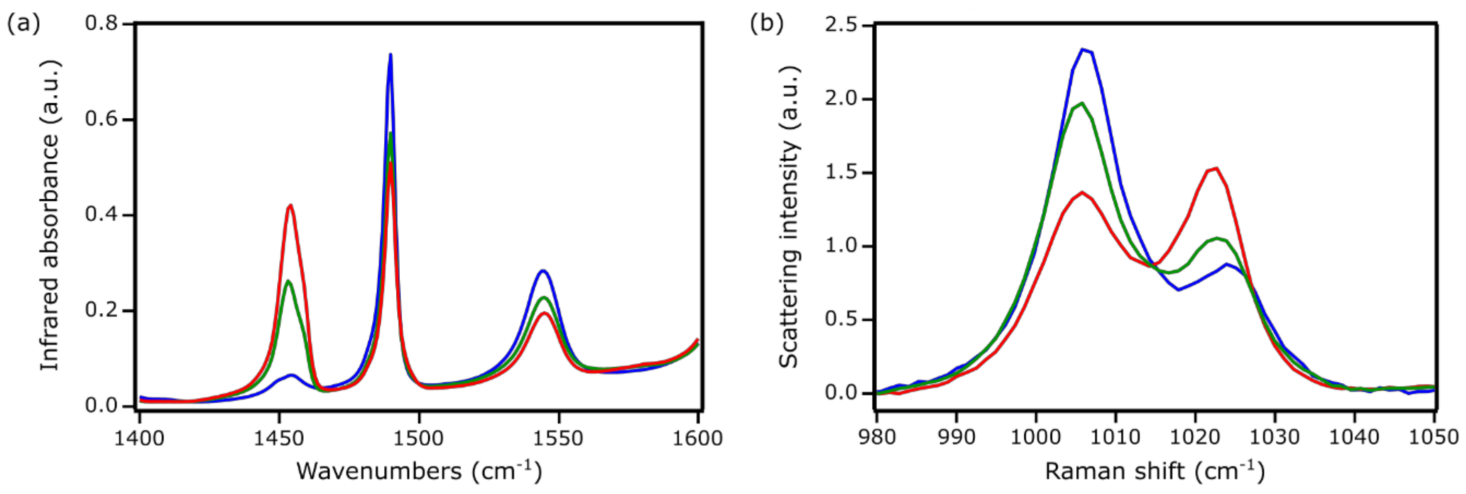

Figure 1. (a) FTIR and (b) spontaneous Raman spectra of pyridine chemisorbed in ZSM-5 zeolites after desorption at $150{ }^{\circ} \mathrm{C}$ under vacuum (blue: Zn000, green: Zn030, red: Zn600). The FTIR and Raman spectra were acquired at $150^{\circ} \mathrm{C}$ under vacuum and in ambient conditions, respectively. 
In a similar way to FTIR spectroscopy, the interactions of pyridine with different types of acid sites can be distinguished using the strong resonances of the ring breathing modes $\left(900-1100 \mathrm{~cm}^{-1}\right)$ in Raman spectroscopy [41-44]. The influence of different types of interactions on the ring breathing modes of pyridine can be illustrated with the Raman spectra of the molecule in different solutions (Figure S4). Interactions with water, $\mathrm{HCl}$, and $\mathrm{ZnCl}_{2}$ affect the breathing mode $v_{1}\left(991 \mathrm{~cm}^{-1}\right)$ and the in-plane deformation mode $v_{12}\left(1030 \mathrm{~cm}^{-1}\right)$ of pyridine. More specifically, in solution, the $v_{1}$ mode is shifted at increasingly higher frequencies upon hydrogen-bonding with water $\left(1002 \mathrm{~cm}^{-1}\right)$, protonation by a Brønsted acid $\left(1010 \mathrm{~cm}^{-1}\right)$, and formation of a complex with a Lewis acid $\left(1019 \mathrm{~cm}^{-1}\right)$. These measurable shifts, originating from changes in geometry and the direct effect of the ligand on the force constant, can thus be exploited to distinguish the different interactions of pyridine with its environment $[45,46]$.

The protonated and Zn-containing ZSM-5 zeolites were loaded with liquid pyridine and characterized with Raman spectroscopy after evacuation at $150{ }^{\circ} \mathrm{C}$ to remove the physisorbed species (Figure 1b). The Raman spectrum of Zn000 displays one main band at $1006 \mathrm{~cm}^{-1}$ assigned to the $v_{1}$ mode of pyridinium cation formed at Brønsted acid sites (called pyridinium cation hereafter) and a broad feature centered around $1023 \mathrm{~cm}^{-1}$ consisting of the overlap of the $v_{12}$ mode of the pyridinium cation and the $v_{1}$ mode of pyridine complexed with Lewis acid sites (called complexed pyridine hereafter). The intensity of the band at $1006 \mathrm{~cm}^{-1}$ progressively decreases upon the introduction of zinc species in ZSM-5 zeolites, whereas an increase is observed in the Raman signal at $1023 \mathrm{~cm}^{-1}$. This increase is ascribed to the higher concentration of Lewis acid sites in the Zn-exchanged zeolites, which give rise to a more important contribution of the $v_{1}$ mode of complexed pyridine to the Raman spectrum. These results are qualitatively in agreement with FTIR measurements. The differences in Raman shift with the reference solution measurements are attributed to the local environment created by the zeolite framework. The Raman spectrum of chemisorbed pyridine provides thus insights into the increase in the zinc content of ion-exchanged ZSM-5 materials.

The distribution of acid sites in single ZSM- 5 crystals can be visualized by spatially resolving the Raman signal of chemisorbed pyridinium cation in the ring breathing region. Figure 2a shows the SRS image of Zn000 crystals using the Raman signal at $1006 \mathrm{~cm}^{-1}$. Interestingly, the SRS signal of pyridinium cation is unevenly distributed in single Zn000 crystals. These local inhomogeneities in the SRS signal are explained by the presence of intergrowths in the ZSM-5 crystals (Figure $2 b$ ). Since SRS microscopy has an axial resolution of around $1 \mu \mathrm{m}$, variations in the thickness of the sample will affect the images acquired at a focal plane in the middle of the $1 \mu \mathrm{m}$-thick crystals. Besides these intra-particle variations, the comparison of the SRS spectrum of $10 \mathrm{Zn} 000$ crystals also reveals the existence of interparticle heterogeneities in the acidic properties of the protonated ZSM- 5 zeolite (Figure S5a). Apparent differences are observed in the intensity Raman signal at $1006 \mathrm{~cm}^{-1}$ of the crystal-averaged SRS spectra, suggesting particle-to-particle variations in the average framework $\mathrm{Al}$ content of $\mathrm{Zn} 00$ crystals (Figure S5b). On the other hand, the intensity ratio of the SRS signal at 1006 and $1023 \mathrm{~cm}^{-1}, \mathrm{I}_{1023} / \mathrm{I}_{1006}$, is very similar for the 10 crystals imaged, suggesting that the decrease in Brønsted acidity is not associated with an increase in Lewis acid site density (Table S2). In any case, the contribution of complexed pyridine to the SRS spectrum of pyridine adsorbed in Zn000 crystals is limited, given the low density of Lewis acid sites in this sample (Table 1).

Unlike Brønsted acidity, the distribution of Lewis acid sites cannot be directly inferred from the SRS image of chemisorbed pyridine at $1023 \mathrm{~cm}^{-1}$ due to the overlap of two vibrational modes. Nevertheless, knowing the SRS intensity ratio $\mathrm{I}_{1023} / \mathrm{I}_{1006}$ of the protonated ZSM-5 zeolite enables subtracting the contribution of pyridinium cation to the SRS spectrum at $1023 \mathrm{~cm}^{-1}$ (see details in Appendix A). The spatial distribution of Lewis acid sites introduced in ZSM- 5 crystals upon ion exchange with $\mathrm{Zn}^{2+}$ can thus be visualized using the obtained SRS signal associated with complexed pyridine. Figure 3 shows the Brønsted and Lewis acid site density maps in protonated and Zn-exchanged ZSM- 5 crystals, as well as their morphology observed with SEM. A strong SRS signal at $1006 \mathrm{~cm}^{-1}$ associated with pyridinium cation is observed in Zn000 crystals (Figure 3a). Please note that while a homogeneous 
distribution of chemisorbed pyridine is observed in the bottom left Zn000 crystal, in most cases intra-particle variations are observed (Figure S5b). In contrast, the density of Lewis acidity obtained after removing the pyridinium cation contribution from the $1023 \mathrm{~cm}^{-1}$ signal is very low. A measurable increase in the SRS signal from complexed pyridine is observed in crystals exchanged with zinc nitrate for $30 \mathrm{~min}$ (Figure 3b,c). However, the introduction of $\mathrm{Zn}^{2+}$ species at cation-exchange sites in the ZSM-5 framework is not uniform. Moreover, no clear correlation between the morphological features (such as intergrowths) and the SRS signal corresponding to Lewis acidity are observed. Extending the exchange time to $6 \mathrm{~h}$ further increases Lewis acid site density at the expense of Brønsted acidity (Figure 3d,e). However, counterintuitively, the spatial distribution of $\mathrm{Zn}^{2+}$ species is not progressively homogenized with prolonged exchange time. On the contrary, the local heterogeneities are even more substantial in Zn600 crystals. Indeed, SRS images reveal sharp differences between crystals in the density of pyridine chemisorbed to Lewis acid sites. Moreover, significant local differences in Lewis acidity are observed within Zn600 crystals.

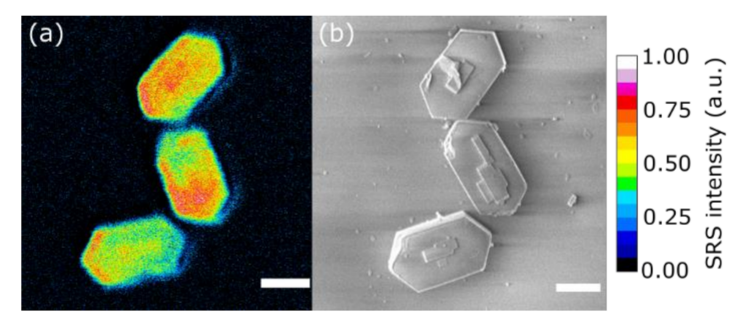

Figure 2. (a) SRS images at $1006 \mathrm{~cm}^{-1}$ of chemisorbed pyridine in Zn000 crystals after desorption at $150^{\circ} \mathrm{C}$ under vacuum. The image was acquired in ambient conditions. (b) Scanning electron microscopy (SEM) image of the morphology of the crystals.

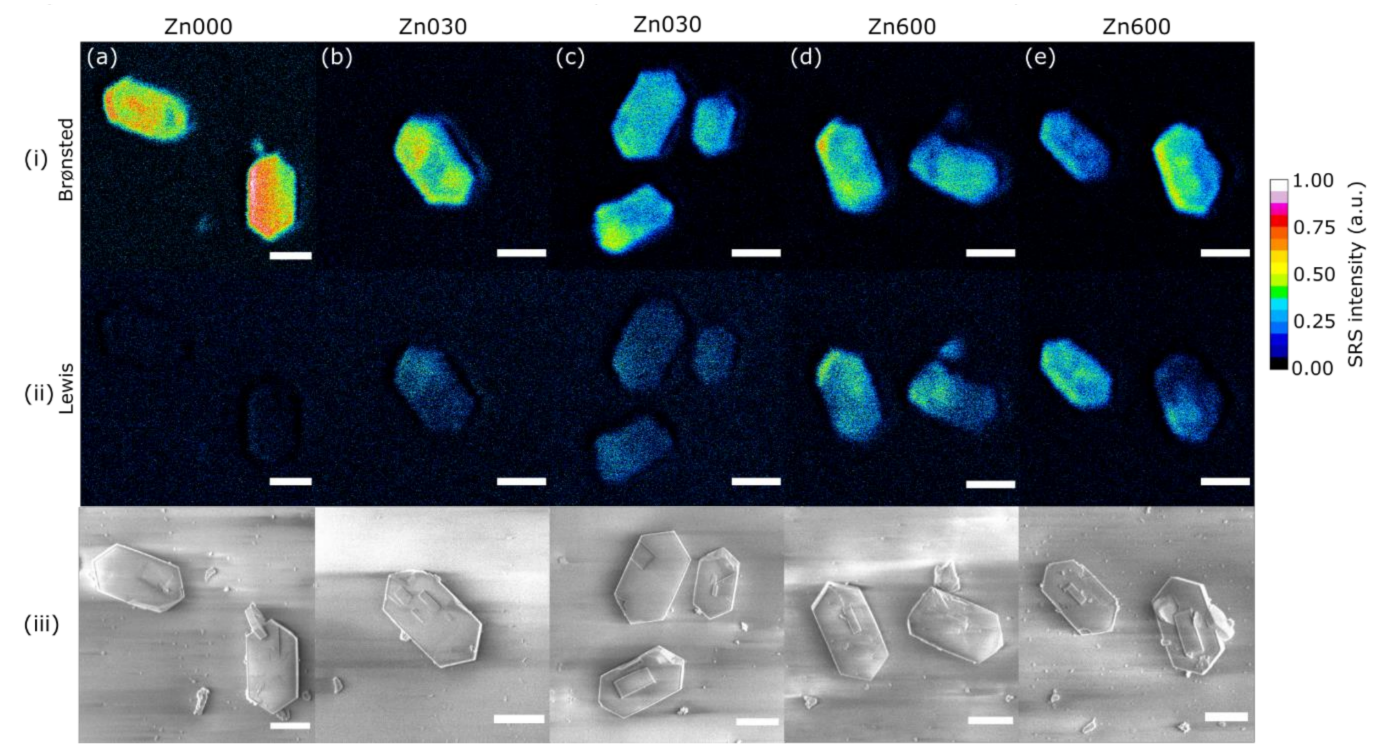

Figure 3. SRS mapping of (i) pyridinium cation $\left(\mathrm{I}_{1006}\right)$ and (ii) complexed pyridine $\left(\mathrm{I}_{1023}-\mathrm{I}_{1006}\left[\mathrm{I}_{1023} / \mathrm{I}_{1006}\right]_{\mathrm{Zn} 000}\right.$, see supporting information for details) and (iii) SEM image of the corresponding morphology for ZSM-5 crystals at different exchange time. (a) Zn000, (b,c) Zn030, and (d,e) Zn600.

The extent of the observed interparticle heterogeneities in Brønsted and Lewis acidity can be evaluated by plotting the measured amounts of both types of acid sites in individual crystals (Figure 4). As seen in the SRS images, the concentration of Lewis acid sites in single ZSM-5 crystals increases and becomes more inhomogeneous with the exchange time. On the other hand, the average Brønsted acidity decreases and becomes more uniform between crystals (Table 2). 


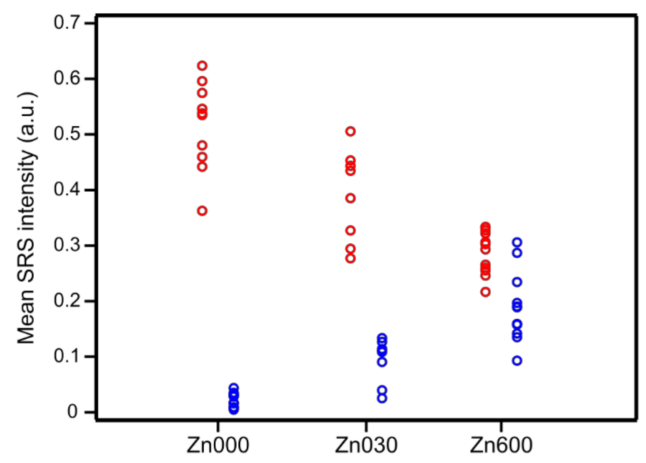

Figure 4. Evolution of the mean SRS intensity of pyridinium cation (red) and complexed pyridine (blue) for single ZSM-5 crystals as a function of the Zn exchange time. The mean SRS intensity of Lewis acidity is offset by $5 \mathrm{~min}$ for clarity.

Table 2. Mean SRS intensity of the $v_{1}$ mode of pyridine chemisorbed on Brønsted and Lewis acid sites.

\begin{tabular}{cccc}
\hline & \multicolumn{3}{c}{ Mean SRS Intensity (a.u.) } \\
\cline { 2 - 4 } & Zn000 & Zn030 & Zn600 \\
\hline Brønsted acid sites & $0.50 \pm 0.09$ & $0.38 \pm 0.08$ & $0.28 \pm 0.04$ \\
\hline Lewis acid sites & $0.02 \pm 0.02$ & $0.09 \pm 0.03$ & $0.19 \pm 0.06$ \\
\hline
\end{tabular}

The relationship between the Lewis acidity and the total acid site density in Zn600 crystals was assessed to rationalize the observed variability in the mean SRS signal. Figure 5a shows the evolution of the mean SRS signal of complexed pyridine with the mean SRS signal of both complexed pyridine and pyridinium cation. A positive correlation is observed, as the SRS signal associated with Lewis acid sites increases linearly with the total acid site density. Since the latter is related to the Al content of Zn600 crystals, this suggests that a higher amount of Lewis acid sites are introduced in Al-rich ZSM- 5 crystals and crystal regions upon Zn exchange. Interparticle variations in the mean SRS signal of complexed pyridine thus arise from differences in the average $\mathrm{Al}$ content in the parent crystals. Likewise, the observed intra-particle heterogeneities in the Lewis acid site density are therefore ascribed to local variations in the $\mathrm{Al}$ content in ZSM-5 crystals.
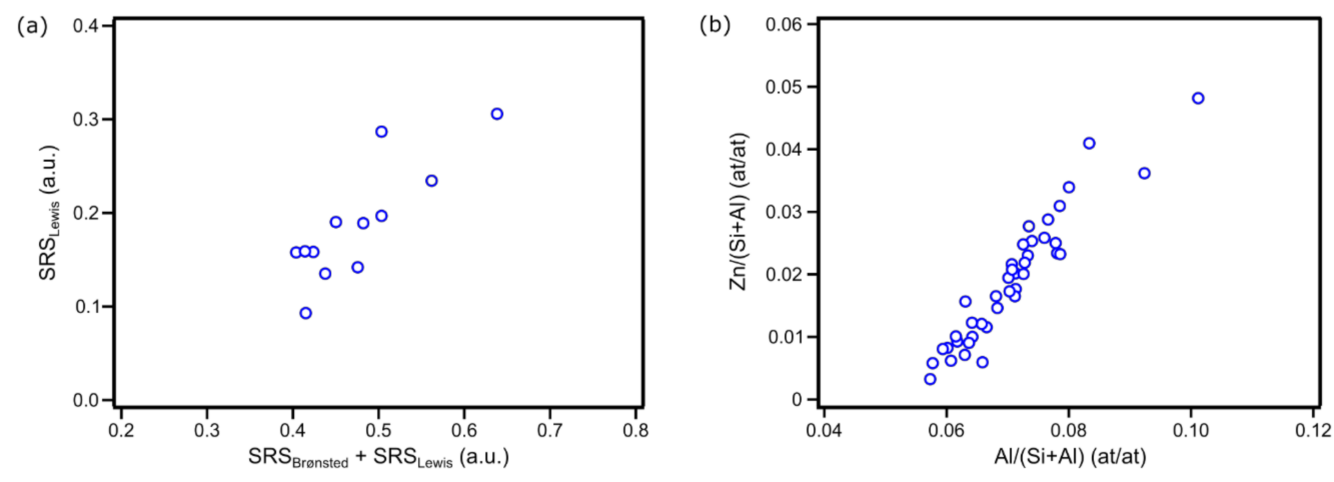

Figure 5. (a) Evolution of the SRS signal of complexed pyridine as a function of the total SRS signal (pyridinium cation and complexed pyridine) in Zn600 crystals. (b) Evolution of the Zn loading $(\mathrm{Zn} /(\mathrm{Si}+\mathrm{Al})$ ratio) as a function of the $\mathrm{Al}$ content $(\mathrm{Al} /(\mathrm{Si}+\mathrm{Al})$ ratio) in $\mathrm{Zn} 600$ crystals in $\mathrm{Zn} 600$ crystals, quantified by point EDX measurements.

The correlation between the Lewis acid site density and the total acidity implies that the local $\mathrm{Al}$ content of ZSM- 5 crystals dictates the $\mathrm{Zn}$ loading after ion exchange. To further explore this relationship, the elemental composition of Zn600 crystals was determined by point-measurements of 
their EDX spectrum (Figure S6). The atomic ratios of $\mathrm{Si}, \mathrm{Al}, \mathrm{O}$, and $\mathrm{Zn}$ were quantified by analyzing point EDX spectra acquired on different crystals. Using the same approach as van der Wal et al., the $\mathrm{Al}$ and Zn content of Zn600 crystals are presented relative to the Si content [47]. Figure 5 shows that the amount of zinc incorporated in Zn600 crystals increases linearly with the compositional ratio of $\mathrm{Al} /(\mathrm{Al}+\mathrm{Si})$. This supports the hypothesis that $\mathrm{Zn}$ exchange occurs preferentially in ZSM- 5 crystals with a higher $\mathrm{Al}$ content. Thus, the observed inter- and intra-particle heterogeneities in Lewis acid site density originate from local variations in the Al content in the ZSM- 5 crystals. These observations are in line with previous scanning transmission electron microscopy (STEM) characterization of a Pt/zeolite $Y$ bifunctional catalyst $[26,47]$. However, in this case, SRS microscopy and SEM-EDX were used to characterize $\mathrm{Zn}^{2+}$ species at cation-exchange sites in the ZSM- 5 framework instead of nanoparticles.

\section{Conclusions}

In conclusion, the spatial distribution of Lewis acid sites was resolved at the single-particle level for the first time with stimulated Raman scattering microscopy, using pyridine as a probe molecule. Lewis acidity introduced in ZSM- 5 crystals by $\mathrm{Zn}^{2+}$ ion exchange was mapped with SRS microscopy using ring breathing modes of chemisorbed pyridine. The SRS images of protonated ZSM-5 zeolite reveal the inhomogeneous distribution of Brønsted acid sites in the few microns-sized crystals. Further analysis of the ion-exchanged materials highlights the inhomogeneous distribution of Lewis acid sites in ZSM- 5 crystals upon the introduction of $\mathrm{Zn}^{2+}$ species. The significant intraand interparticle variability in acidic properties after ion exchange are linked to local variations in the $\mathrm{Al}$ content of parent crystals. These results highlight the influence of the crystal composition on the introduction of additional Lewis acid sites in ZSM-5 by ion exchange. These insights can be exploited in the rational preparation of metal-exchanged zeolite with optimized active site distribution. Thus, spatially resolving chemisorbed probe molecules with SRS microscopy is a powerful tool, complementary to bulk-scale techniques, to unravel the acidic properties of heterogeneous catalysts.

\section{Materials and Methods}

\subsection{Material Preparation}

$\mathrm{NH}_{4}-\mathrm{ZSM}-5$ zeolite ( $\left.\mathrm{NH}_{4} \mathrm{CZP} 55\right)$ was provided by Clariant (Bruckmühl, Germany). The crystals were used as such for the preparation of protonated and Zn-exchanged ZSM-5. The protonated zeolite $\mathrm{Zn} 000$ was obtained by calcination of the parent sample at $450{ }^{\circ} \mathrm{C}\left(5^{\circ} \mathrm{C} / \mathrm{min}, 6 \mathrm{~h}\right)$. The $\mathrm{Zn}$-exchanged zeolites $\mathrm{Zn030}$ and $\mathrm{Zn} 600$ were prepared based on a previously reported protocol [9]. $\mathrm{NH}_{4}$-ZSM-5 powder was stirred in an aqueous solution of $\mathrm{Zn}\left(\mathrm{NO}_{3}\right)_{2}\left(0.1 \mathrm{M}, \mathrm{m}_{\text {liquid }} / \mathrm{m}_{\text {solid }}=40\right)$ at $80^{\circ} \mathrm{C}$ for $30 \mathrm{~min}$ and $6 \mathrm{~h}$, respectively. After filtration, the samples were dried at $80^{\circ} \mathrm{C}$ overnight and calcined at $450{ }^{\circ} \mathrm{C}$ $\left(5^{\circ} \mathrm{C} / \mathrm{min}, 6 \mathrm{~h}\right)$.

\subsection{Bulk-Scale Characterization}

The elemental composition of the samples was determined by X-ray fluorescence analysis (Bruker S8 TIGER 4k).

Nitrogen physisorption measurements were performed on a Micromeritics 3Flex surface analyzer and carried out at $-196^{\circ} \mathrm{C}$. Before the measurements, the samples (50-100 mg) were outgassed for $10 \mathrm{~h}$ at $180^{\circ} \mathrm{C}$ and $10^{-1}$ mbar vacuum.

Powder X-ray diffraction data was recorded on a Malvern PANalytical Empyrean diffractometer equipped with a PIXcel3D solid-state detector using a $\mathrm{Cu}$ anode $\left(\mathrm{Cu} \mathrm{K} \mathrm{K}_{\alpha 1}: 1.5406 \AA\right.$ 和 $\mathrm{K}_{\alpha 2}: 1.5444 \AA$ ) . Samples were loaded onto a 96 -well sample holder, and patterns were recorded at room temperature in transmission geometry (Debye-Scherrer; $\theta-\theta$ scan) within a $1.3-45^{\circ} 2 \theta$ range using a step size of $0.013^{\circ}$.

IR experiments were performed on a Nicolet 6700 spectrometer equipped with a DTGS detector (128 scans; resolution of $2 \mathrm{~cm}^{-1}$ ). Self-supporting wafers were pretreated in vacuum at $400{ }^{\circ} \mathrm{C} \mathrm{K}$ for $1 \mathrm{~h}\left(5^{\circ} \mathrm{C} / \mathrm{min}\right)$ before measurements. The acidity of the catalysts was analyzed using pyridine as a 
probe. After pretreatment at $400 \mathrm{~K}$, the samples were saturated with about $25-28$ mbar of pyridine vapor at $50^{\circ} \mathrm{C}$ for $20 \mathrm{~min}$. The evacuated samples containing the adsorbed pyridine were heated up to $150^{\circ} \mathrm{C}$, kept for $20 \mathrm{~min}$, and then IR spectra were recorded. The integrated molar extinction coefficients used in acidity quantification were $1.67 \mathrm{~cm}^{-1} \mu \mathrm{mol}^{-1}$ and $2.22 \mathrm{~cm}^{-1} \mu \mathrm{mol}^{-1}$ for the $1545 \mathrm{~cm}^{-1}$ band characteristic for Brønsted acid sites and $1455 \mathrm{~cm}^{-1}$ band characteristic for Lewis acid sites, respectively (according to the data reported in C. A. Emeis, J. Catal., 1993, 141, 347-354).

UV-visible diffuse reflectance spectra were recorded on a Perkin Elmer Lambda 950 UV-VIS-NIR spectrophotometer with the $150 \mathrm{~mm}$ integrating sphere accessory in the wavelength range between $250 \mathrm{~nm}$ to $600 \mathrm{~nm}$.

\subsection{Spontaneous Raman Microspectroscopy and SRS Imaging-Sample Preparation}

Zeolite powder was placed in a glass vial and then calcined an ashing furnace (Nabertherm LVT $3 / 11)$ to remove any impurities, using a three-step temperature program $\left(80^{\circ}\right.$ for $1 \mathrm{~h}, 120^{\circ}$ for $1 \mathrm{~h}, 450^{\circ} \mathrm{C}$ for $50 \mathrm{~h}$ ) with a temperature ramp of $1{ }^{\circ} \mathrm{C} / \mathrm{min}$. The sample was removed from the oven at $450{ }^{\circ} \mathrm{C}$ and immediately placed in a desiccator under nitrogen. Once cooled down to room temperature, the sample was loaded with liquid pyridine. The vial was sealed, and the sample left to equilibrate for $24 \mathrm{~h}$. After equilibration, the content of the vial was evacuated at $150^{\circ} \mathrm{C}$ for two hours to remove liquid as well as physisorbed pyridine. The powder recovered was then disposed on a \#1 glass coverslip before spontaneous and stimulated Raman scattering experiments in ambient conditions.

\subsection{Spontaneous Raman Microspectroscopy}

The Raman spectrum pyridine chemisorbed in Meso-MOR crystals was acquired with a confocal Raman microscope (MonoVista CRS+, S\&I Instruments). The $532 \mathrm{~nm}$ laser line (Cobolt Samba, Norfolk, UK) was used as the excitation sourced, and the laser beam was focused on the sample with a $100 \times 0.9$ NA objective lens (MPLN100X, Olympus, Antwerpen, Belgia). After being collected by the same objective lens, the backward Raman scattering signal was passed through a $100-\mu \mathrm{m}$ confocal pinhole and sent into a monochromator (Princeton Instruments, Trenton, NJ, USA) equipped with a 1200 grooves/nm grating. The signal was then recorded with a charge-coupled device (CCD) camera (Newton 920, Andor, Belfast, UK). The spectrum of the sample was obtained by averaging three acquisitions of $10 \mathrm{~s}$. The Raman bands were fitted with Lorentzian curves using the MultiPeak Fit 2 tool of Igor Pro.

\subsection{Stimulated Raman Scattering Microscopy}

The light used in the SRS microscope consist of the $1064 \mathrm{~nm}, 7 \mathrm{ps}$ and $80 \mathrm{MHz}$ repetition rate output of a Nd:YVO4 laser (picoTRAIN, High-Q, Rankweil, Austria) and an optical parametric oscillator (OPO) (Levante Emerald, APE-Berlin, Germany) synchronously pumped by the $532 \mathrm{~nm}$ output of the of Nd:YVO4 laser. The OPO output was tuned in the 957-963 nm window to probe the ring breathing modes of pyridine. The amplitude of the $1064 \mathrm{~nm}$ laser was modulated at $9.7 \mathrm{MHz}$ using a Pockell Cell (model 360-80, ConOptics, Danbury, CT, USA) and a function generator (model 29, Waveteck, Hsinchu, Taiwan) before spatial and temporal overlap with the OPO output. The SRS images were acquired in transmission on an upright optical microscope (BX61WI/FV1000, Olympus) using a water immersion $25 \times 1.05$ NA objective (XLPLAN, Olympus) and an oil immersion 1.4 NA condenser (U-UCD8, Olympus). Both beams had a power in focus of $45 \mathrm{~mW}$. A dichroic mirror (FF750, Semrock, New York, NY, USA) was used to reflect the transmitted beams, and the $1064 \mathrm{~nm}$ beam was blocked with a bandpass filter (ChromaTechnology, Bellows Falls, VT, USA, CARS 890/220 m). A silicon PIN photodiode (S8650, Hamamatsu, Hamamatsu, Japan) on which a reverse bias of $60 \mathrm{~V}$ was applied was used to detect the stimulated Raman loss of the OPO beam. The obtained photocurrent was filtered (Mini-Circuits, Brooklyn, NY, USA, BLP-1.9), demodulated (HF2LI, Zurich Instrument, Zurich, Switzerland) and sent to an analog-to-digital converter (FV-10-ANALOG, Olympus) synchronized with the microscope. 


\subsection{SEM-Sample Preparation}

The samples previously imaged with SRS microscopy were recovered and used as such, after removing the immersion water from the glass coverslip.

\subsection{Scanning Electron Microscopy}

The morphology of the crystals was observed using a scanning electron microscope (FEI Quanta 250 FEG) with an acceleration voltage of $2 \mathrm{kV}$.

Supplementary Materials: The following are available online at http://www.mdpi.com/2073-4344/10/11/1331/s1, Figure S1: Nitrogen adsorption and desorption isotherms of the protonated and zinc-exchanged ZSM-5 zeolites, Figure S2: XRD patterns of the protonated and zinc-exchanged ZSM-5 zeolites, Figure S3: UV-visible diffuse reflectance spectra of the protonated and zinc-exchanged ZSM-5 zeolites as well as nanoparticles of ZnO, Figure S4: Spontaneous Raman spectra of pyridine in different environments, Figure S5: SRS images and spectra of chemisorbed pyridine in Zn000 crystals after desorption, Figure S6: Typical EDX spectrum of a Zn600 crystal acquired by point-analysis, Table S1: Textural properties of the protonated and zinc-exchanged ZSM- 5 zeolites determined from nitrogen physisorption measurements, Table S2: Statistical analysis of the intensity ratio of the SRS signal at 1006 and $1023 \mathrm{~cm}^{-1}$

Author Contributions: Conceptualization, G.F. and M.B.J.R.; Data curation, G.F.; Formal analysis, G.F.; Investigation, G.F.; Methodology, G.F. and M.B.J.R.; Validation, M.B.J.R.; Visualization, G.F.; Writing-original draft, G.F.; Writing - review \& editing, G.F. and M.B.J.R. Both authors have read and agreed to the published version of the manuscript.

Funding: The authors thank FWO for the investment in microscopy (AKUL/15/15-G0H0816N and G0H6316N-ZW15_09) and financial support from the KU Leuven Research Fund (C14/15/053 and C14/19/079).

Acknowledgments: Silke Sauerbeck (Clariant, Bruckmühl, Germany) is kindly acknowledged for providing the $\mathrm{NH}_{4}$-ZSM-5 zeolite. The authors thank Michaël Gebruers for the assistance with the XRD and XRF measurements.

Conflicts of Interest: The authors declare no conflict of interest. The funders had no role in the design of the study; in the collection, analyses, or interpretation of data; in the writing of the manuscript, or in the decision to publish the results.

\section{Appendix A}

The SRS signal of chemisorbed pyridine in the $950-1050 \mathrm{~cm}^{-1}$ window arises from the $v_{1}$ and $v_{12}$ modes. The intensity of the signal can be expressed as follow:

$$
\begin{aligned}
& \mathrm{I}_{1006}=\sigma_{\mathrm{BAS}, 1006} \mathrm{C}_{\mathrm{BAS}}+\sigma_{\mathrm{LAS}, 1006} \mathrm{C}_{\mathrm{LAS}} \\
& \mathrm{I}_{1023}=\sigma_{\mathrm{BAS}, 1023} \mathrm{C}_{\mathrm{BAS}}+\sigma_{\mathrm{LAS}, 1023 \mathrm{C}_{\mathrm{LAS}}}
\end{aligned}
$$

where $c_{B A S}$ and $c_{L A S}$ stand for the concentration of Brønsted and Lewis acid sites, respectively. Since $c_{\text {LAS }}$ is very low in $\mathrm{Zn} 000$, the intensity ratio $\mathrm{I}_{1023} / \mathrm{I}_{1006}$ can be expressed as:

$$
\left(\frac{\mathrm{I}_{1023}}{\mathrm{I}_{1006}}\right)_{\mathrm{Zn} 00}=\frac{\sigma_{\mathrm{BAS}, 1023}}{\sigma_{\mathrm{BAS}, 1006}}
$$

The SRS intensity at $1023 \mathrm{~cm}^{-1}$ can thus be expressed as:

$$
\mathrm{I}_{1023}=\left(\frac{\mathrm{I}_{1023}}{\mathrm{I}_{1006}}\right)_{\mathrm{Zn} 00} \sigma_{\mathrm{BAS}, 1006} \mathrm{C}_{\mathrm{BAS}}+\sigma_{\mathrm{LAS}, 1023 \mathrm{C}_{\mathrm{LAS}}}
$$

Therefore, the contribution of pyridine chemisorbed to Lewis acid sites can be extracted from the SRS spectrum, using the following expression:

$$
\sigma_{\mathrm{LAS}, 1023} \mathrm{C}_{\mathrm{LAS}}=\mathrm{I}_{1023}-\left(\frac{\mathrm{I}_{1023}}{\mathrm{I}_{1006}}\right)_{\mathrm{Zn} 00} \mathrm{I}_{1006}
$$


To account for variability in the Lewis acid site density in the parent crystals, the minimal $\mathrm{I}_{1023} / \mathrm{I}_{1006}$ ratio observed (0.39) was used.

\section{References}

1. Bartholomew, C.H.; Farrauto, R.J. Fundamentals of Industrial Catalytic Processes; John Wiley \& Sons: Hoboken, NJ, USA, 2006; ISBN 978-7-80471-457-9.

2. Corma, A.; García, H. Lewis acids: From conventional homogeneous to green homogeneous and heterogeneous catalysis. Chem. Rev. 2003, 103, 4307-4366. [CrossRef] [PubMed]

3. Dapsens, P.Y.; Mondelli, C.; Pérez-Ramírez, J. Design of Lewis-acid centres in zeolitic matrices for the conversion of renewables. Chem. Soc. Rev. 2015, 44, 7025-7043. [CrossRef] [PubMed]

4. Luo, H.Y.; Lewis, J.D.; Román-Leshkov, Y. Lewis acid zeolites for biomass conversion: Perspectives and challenges on reactivity, synthesis, and stability. Annu. Rev. Chem. Biomol. Eng. 2016, 7, 663-692. [CrossRef] [PubMed]

5. Li, G.; Pidko, E.A. The nature and catalytic function of cation sites in zeolites: A computational perspective. Chem CatChem 2019, 11, 134-156. [CrossRef]

6. Mole, T.; Anderson, J.R.; Creer, G. The reaction of propane over ZSM-5-H and ZSM-5-Zn zeolite catalysts. Appl. Catal. 1985, 17, 141-154. [CrossRef]

7. Ono, Y.; Adachi, H.; Senoda, Y. Selective conversion of methanol into aromatic hydrocarbons over zinc-exchanged ZSM-5 zeolites. J. Chem. Soc. Faraday Trans. 1 Phys. Chem. Condens. Phases 1988, 84, 1091-1099. [CrossRef]

8. Ono, Y.; Kanae, K. Transformation of butanes over ZSM-5 zeolites. Part 2.-Formation of aromatic hydrocarbons over Zn-ZSM-5 and Ga-ZSM-5. J. Chem. Soc. Faraday Trans. 1991, 87, 669-675. [CrossRef]

9. Niu, X.; Gao, J.; Miao, Q.; Dong, M.; Wang, G.; Fan, W.; Qin, Z.; Wang, J. Influence of preparation method on the performance of Zn-containing HZSM-5 catalysts in methanol-to-aromatics. Microporous Mesoporous Mater. 2014, 197, 252-261. [CrossRef]

10. Biscardi, J.A.; Iglesia, E. Structure and function of metal cations in light alkane reactions catalyzed by modified H-ZSM5. Catal. Today 1996, 31, 207-231. [CrossRef]

11. Biscardi, J.A.; Meitzner, G.D.; Iglesia, E. Structure and density of active Zn species in Zn/H-ZSM5 Propane aromatization catalysts. J. Catal. 1998, 179, 192-202. [CrossRef]

12. Tabacchi, G. Supramolecular organization in confined nanospaces. ChemPhysChem 2018, 19, 1249-1297. [CrossRef] [PubMed]

13. Bryce, D.L. NMR crystallography: Structure and properties of materials from solid-state nuclear magnetic resonance observables. IUCrJ 2017, 4, 350-359. [CrossRef] [PubMed]

14. Morra, E.; Berlier, G.; Borfecchia, E.; Bordiga, S.; Beato, P.; Chiesa, M. Electronic and geometrical structure of $\mathrm{Zn}+$ ions stabilized in the Porous structure of Zn-loaded Zeolite H-ZSM-5: A multifrequency CW and Pulse EPR study. J. Phys. Chem. C 2017, 121, 14238-14245. [CrossRef]

15. van Bokhoven, J.A.; Lamberti, C. Structure of aluminum, iron, and other heteroatoms in zeolites by X-ray absorption spectroscopy. Coord. Chem. Rev. 2014, 277-278, 275-290. [CrossRef]

16. Hagen, A.; Hallmeier, K.-H.; Hennig, C.; Szargan, R.; Inui, T.; Roessner, F. State of Zinc in MFI Type Zeolites Characterized by XANES and EXAFS. In Studies in Surface Science and Catalysis; Beyer, H.K., Karge, H.G., Kiricsi, I., Nagy, J.B., Eds.; Catalysis by Microporous Materials; Elsevier: Amsterdam, The Netherlands, 1995; Volume 94, pp. 195-202. [CrossRef]

17. Weckhuysen, B.M. Chemical imaging of spatial heterogeneities in catalytic solids at different length and time scales. Angew. Chem. Int. Ed. 2009, 48, 4910-4943. [CrossRef] [PubMed]

18. Buurmans, I.L.C.; Weckhuysen, B.M. Heterogeneities of individual catalyst particles in space and time as monitored by spectroscopy. Nat. Chem. 2012, 4, 873-886. [CrossRef] [PubMed]

19. Meirer, F.; Weckhuysen, B.M. Spatial and temporal exploration of heterogeneous catalysts with synchrotron radiation. Nat. Rev. Mater. 2018, 3, 324-340. [CrossRef]

20. Janssen, K.P.F.; Cremer, G.D.; Neely, R.K.; Kubarev, A.V.; Loon, J.V.; Martens, J.A.; Vos, D.E.D.; Roeffaers, M.B.J.; Hofkens, J. Single molecule methods for the study of catalysis: From enzymes to heterogeneous catalysts. Chem. Soc. Rev. 2014, 43, 990-1006. [CrossRef] 
21. Stavitski, E.; Weckhuysen, B.M. Infrared and Raman imaging of heterogeneous catalysts. Chem. Soc. Rev. 2010, 39, 4615-4625. [CrossRef]

22. Munnik, P.; de Jongh, P.E.; de Jong, K.P. Recent developments in the synthesis of supported catalysts. Chem. Rev. 2015, 115, 6687-6718. [CrossRef]

23. Plessers, E.; Stassen, I.; Sree, S.P.; Janssen, K.P.F.; Yuan, H.; Martens, J.; Hofkens, J.; De Vos, D.; Roeffaers, M.B.J. Resolving interparticle heterogeneities in composition and hydrogenation performance between individual supported silver on silica catalysts. ACS Catal. 2015, 5, 6690-6695. [CrossRef] [PubMed]

24. Plessers, E.; van den Reijen, J.E.; de Jongh, P.E.; de Jong, K.P.; Roeffaers, M.B.J. Origin and abatement of heterogeneity at the support granule scale of silver on silica catalysts. ChemCatChem 2017, 9, 4562-4569. [CrossRef]

25. van der Bij, H.E.; Aramburo, L.R.; Arstad, B.; Dynes, J.J.; Wang, J.; Weckhuysen, B.M. Phosphatation of Zeolite H-ZSM-5: A combined microscopy and spectroscopy study. ChemPhysChem 2014, 15, 283-292. [CrossRef] [PubMed]

26. Zečević, J.; van der Eerden, A.M.J.; Friedrich, H.; de Jongh, P.E.; de Jong, K.P. Heterogeneities of the Nanostructure of Platinum/Zeolite Y catalysts revealed by electron tomography. ACS Nano 2013, 7, 3698-3705. [CrossRef]

27. Mehdad, A.; Lobo, R.F. Ethane and ethylene aromatization on zinc-containing zeolites. Catal. Sci. Technol. 2017, 7, 3562-3572. [CrossRef]

28. Roeffaers, M.B.J.; Sels, B.F.; Uji-i, H.; Blanpain, B.; L’hoëst, P.; Jacobs, P.A.; De Schryver, F.C.; Hofkens, J.; De Vos, D.E. Space- and time-resolved visualization of acid catalysis in ZSM-5 crystals by fluorescence microscopy. Angew. Chem. 2007, 119, 1736-1739. [CrossRef]

29. Kox, M.H.F.; Stavitski, E.; Groen, J.C.; Pérez-Ramírez, J.; Kapteijn, F.; Weckhuysen, B.M. Visualizing the crystal structure and locating the catalytic activity of micro- and mesoporous ZSM-5 Zeolite Crystals by using in situ optical and fluorescence microscopy. Chem. Eur. J. 2008, 14, 1718-1725. [CrossRef]

30. Kennes, K.; Demaret, C.; Van Loon, J.; Kubarev, A.V.; Fleury, G.; Sliwa, M.; Delpoux, O.; Maury, S.; Harbuzaru, B.; Roeffaers, M.B.J. Assessing Inter and Intra-Particle Heterogeneity in Alumina-Poor H-ZSM-5 Zeolites. ChemCatChem 2017, 9, 3440-3445. [CrossRef]

31. Kerssens, M.M.; Sprung, C.; Whiting, G.T.; Weckhuysen, B.M. Selective staining of zeolite acidity: Recent progress and future perspectives on fluorescence microscopy. Microporous Mesoporous Mater. 2014, 189, 136-143. [CrossRef]

32. Bordiga, S.; Lamberti, C.; Bonino, F.; Travert, A.; Thibault-Starzyk, F. Probing zeolites by vibrational spectroscopies. Chem. Soc. Rev. 2015, 44, 7262-7341. [CrossRef]

33. Aramburo, L.R.; Karwacki, L.; Cubillas, P.; Asahina, S.; de Winter, D.A.M.; Drury, M.R.; Buurmans, I.L.C.; Stavitski, E.; Mores, D.; Daturi, M.; et al. The porosity, acidity, and reactivity of dealuminated Zeolite ZSM-5 at the single particle level: The influence of the Zeolite architecture. Chem. Eur. J. 2011, 17, 13773-13781. [CrossRef] [PubMed]

34. Liu, K.-L.; Kubarev, A.V.; Van Loon, J.; Uji-i, H.; De Vos, D.E.; Hofkens, J.; Roeffaers, M.B.J. Rationalizing interand intracrystal heterogeneities in dealuminated acid mordenite zeolites by stimulated raman scattering microscopy correlated with super-resolution fluorescence microscopy. ACS Nano 2014, 8, 12650-12659. [CrossRef] [PubMed]

35. Berndt, H.; Lietz, G.; Völter, J. Zinc promoted H-ZSM-5 catalysts for conversion of propane to aromatics II. Nature of the active sites and their activation. Appl. Catal. Gen. 1996, 146, 365-379. [CrossRef]

36. Almutairi, S.M.T.; Mezari, B.; Magusin, P.C.M.M.; Pidko, E.A.; Hensen, E.J.M. Structure and reactivity of Zn-modified ZSM-5 Zeolites: The importance of clustered cationic Zn complexes. ACS Catal. 2012, 2, 71-83. [CrossRef]

37. Bi, Y.; Wang, Y.; Chen, X.; Yu, Z.; Xu, L. Methanol aromatization over HZSM-5 catalysts modified with different zinc salts. Chin. J. Catal. 2014, 35, 1740-1751. [CrossRef]

38. Wei, Z.; Chen, L.; Cao, Q.; Wen, Z.; Zhou, Z.; Xu, Y.; Zhu, X. Steamed Zn/ZSM-5 catalysts for improved methanol aromatization with high stability. Fuel Process. Technol. 2017, 162, 66-77. [CrossRef]

39. Pinilla-Herrero, I.; Borfecchia, E.; Holzinger, J.; Mentzel, U.V.; Joensen, F.; Lomachenko, K.A.; Bordiga, S.; Lamberti, C.; Berlier, G.; Olsbye, U.; et al. High Zn/Al ratios enhance dehydrogenation vs hydrogen transfer reactions of Zn-ZSM-5 catalytic systems in methanol conversion to aromatics. J. Catal. 2018, 362, 146-163. [CrossRef] 
40. Valecillos, J.; Epelde, E.; Albo, J.; Aguayo, A.T.; Bilbao, J.; Castaño, P. Slowing down the deactivation of H-ZSM-5 zeolite catalyst in the methanol-to-olefin (MTO) reaction by P or Zn modifications. Catal. Today 2020, 348, 243-256. [CrossRef]

41. Egerton, T.A.; Hardin, A.H.; Sheppard, N. Raman spectra of pyridine adsorbed on a series of ion-exchanged forms of zeolite Y. Can. J. Chem. 1976, 54, 586-598. [CrossRef]

42. Yamada, H.; Yamamoto, Y. Ultraviolet excitation of Raman spectra of pyridines adsorbed on oxides. J. Chem. Soc. Faraday Trans. 1 Phys. Chem. Condens. Phases 1979, 75, 1215-1221. [CrossRef]

43. Ferwerda, R.; van der Maas, J.H.; Hendra, P.J. Pyridine adsorbed on Na-faujasite: A FT-Raman spectroscopic study. J. Phys. Chem. 1993, 97, 7331-7336. [CrossRef]

44. Ferwerda, R.; van der Maas, J.H.; Hendra, P.J. Fourier transform Raman spectroscopy of pyridine adsorbed on faujasites. Vib. Spectrosc. 1994, 7, 37-47. [CrossRef]

45. Ferwerda, R.; van der Maas, J.H.; van Duijneveldt, F.B. Pyridine adsorption onto metal oxides: An ab initio study of model systems. J. Mol. Catal. Chem. 1996, 104, 319-328. [CrossRef]

46. Kassab, E.; Castellà-Ventura, M. Theoretical study of Pyridine and 4,4'-Bipyridine adsorption on the lewis acid sites of alumina surfaces based on Ab Initio and density functional cluster calculations. J. Phys. Chem. B 2005, 109, 13716-13728. [CrossRef] [PubMed]

47. Van der Wal, L.I.; de Jong, K.P.; Zečević, J. The origin of metal loading heterogeneities in Pt/Zeolite Y bifunctional catalysts. ChemCatChem 2019, 11, 4081-4088. [CrossRef]

Publisher's Note: MDPI stays neutral with regard to jurisdictional claims in published maps and institutional affiliations. 